\title{
FUZZY SEBAGAI ALAT BANTU REKOMENDASI PERINGKAT PRODUK PADA KASUS PEMILIHAN PONSEL
}

\author{
Eddy Triswanto Setyoadi, ST., M.Kom.*
}

\begin{abstract}
ABSTRAK
Pada saat ini keberadaan ponsel sebagai salah satu alat komunikasi adalah suatu benda yang tergolong primer bagi banyak orang. Hampir setiap orang yang kita jumpai pasti memiliki dan memanfaatkan alat komunikasi ini. Hal ini menyebabkan semakin tingginya permintaan pasar atas kebutuhan alat komunikasi ini.

Dengan tingginya permintaan pasar atas kebutuhan alat komunikasi ini, maka muncul berbagai jenis dan merek ponsel beserta fitur-fitur yang berkembang mengikuti perkembangan Teknologi Informasi saat ini.

Selain itu perlu dibangun sebuah aplikasi berbasis web yang menggunakan fuzzy sebagai alternatif membantu memberikan rekomendasi pilihan ponsel yang sesuai dengan keinginan calon pembeli. Pada implementasinya, agar memudahkan calon pembeli/pengguna sistem ini, penyampaian informasi tentang kriteria yang di inginkan menggunakan bahasa sehari-hari yang hasilnya disajikan berupa daftar peringkat atau ranking list.
\end{abstract}

Kata Kunci : Ponsel, Fuzzy, Ranking List

\section{PENDAHULUAN}

Pada saat ini keberadaan ponsel sebagai salah satu alat komunikasi adalah suatu benda yang tergolong primer bagi banyak orang. Hampir setiap orang yang kita jumpai pasti memiliki dan memanfaatkan alat komunikasi ini. Hal ini menyebabkan semakin tingginya permintaan pasar atas kebutuhan alat komunikasi ini.

\subsection{Latar Belakang}

Dengan tingginya permintaan pasar atas kebutuhan alat komunikasi ini, maka muncul berbagai jenis dan merek ponsel beserta fitur-fitur yang berkembang mengikuti perkembangan Teknologi Informasi saat ini. Dengan banyaknya jenis, merek, dan fiturfitur maka timbul permasalahan "Ponsel apa yang cocok untuk kebutuhan saya ?”.

Untuk menjawab pertanyaan tersebut di atas maka perlu dibangun sebuah aplikasi berbasis web yang menggunakan fuzzy sebagai alternatif membantu memberikan rekomendasi pilihan ponsel yang sesuai dengan keinginan calon pembeli. Pada implementasinya, agar memudahkan calon pembeli/pengguna sistem ini, penyampaian informasi tentang kriteria yang di inginkan menggunakan bahasa sehari-hari. Agar lebih memudahkan pengguna maka dipilih aplikasi ini dengan menggunakan atau berbasis pada web agar masyarakat/pengguna dapat menggunakan aplikasi ini secara cepat dan efisien serta bisa di akses di manapun juga.

\footnotetext{
* Dosen Pengajar Program Studi S1-Sistem Informasi IKADO
} 


\subsection{Perumusan Masalah}

Kebutuhan input sistem dapat dibagi menjadi 2 yaitu Input Fuzzy dan Input Non Fuzzy. Input Fuzzy adalah data ponsel dimana data ini dapat disebut sebagai variabel fuzzy. Input Non Fuzzy adalah data ponsel yang tidak dapat di-fuzzykan dimana datadata ini bersifat pilihan (Yes/No). Berikut deskripsi dari batasan masalah lebih detil :
A. Input Fuzzy

Tabel Input Fuzzy

\begin{tabular}{|l|l|l|l|}
\hline \multicolumn{1}{|c|}{ Fitur } & \multicolumn{1}{|c|}{ Contoh } & \multicolumn{1}{c|}{ Fuzzy Value } & \multicolumn{1}{c|}{ Satuan } \\
\hline Harga & $\begin{array}{l}500.000 ; \\
2.500 .000\end{array}$ & Murah; Sedang; Mahal & Rupiah \\
\hline Dimensi (PxLxT) & $\begin{array}{l}106.4 \text { x 43.6 x 75 } \\
105.3 \text { x 44.6 x } 60\end{array}$ & Kecil; Sedang; Besar & $\mathrm{mm}^{3}$ \\
\hline Berat & $80 ; 91$ & Ringan; Sedang; Berat & Gram \\
\hline Ukuran Layar & $96 x 68 ; 120 x 240$ & Kecil; Sedang; Besar & Pixel \\
\hline Internal Memory & $8 ; 12$ & Kecil; Sedang; Besar & MB \\
\hline Phonebook Memory & $250 ; 500$ & Sedikit; Sedang; Banyak & Buah \\
\hline Talk Time & $180 ; 240$ & Sebentar; Sedang; Lama & Jam \\
\hline $\begin{array}{l}\text { Standby } \\
\text { Time }\end{array}$ & $360 ; 480$ & Sebentar; Sedang; Lama & Jam \\
\hline Message Length & $160 ; 320$ & Pendek; Sedang; Panjang & Character \\
\hline
\end{tabular}

B. Input Non Fuzzy

- Koneksi : USB, WAP, GPRS, Bluetooth, Infrared, $3 G$

- Kamera

- Pesan : SMS, MMS, Email

- Hiburan : Games, MP3, MP4, Radio

- Eksternal Memori : Micro SD, Mini SD

\subsection{Tujuan dan Manfaat Penelitian}

1. Menerapkan teori fuzzy di dalam kehidupan sehari-hari.

2. Meneliti apakah fuzzy dapat di gunakan sebagai alternatif cara untuk pemberian rekomendasi dalam pengambilan keputusan.

3. Memudahkan calon pembeli dalam memilih ponsel yang sesuai dengan kebutuhannya.

\section{LANDASAN TEORI}

\subsection{Logika Fuzzy}

Logika fuzzy dikatakan sebagai logika baru yang lama, sebab teori tentang logika fuzzy modern dan metodis baru ditemukan beberapa tahun yang lalu, padahal sebenarnya konsep tentang logika fuzzy itu sendiri sudah ada sejak lama. Logika fuzzy adalah suatu cara yang tepat untuk memetakan suatu ruang input ke dalam suatu ruang keluaran.

Ada beberapa alasan mengapa perlu menggunakan logika fuzzy dalam menyelesaikan suatu masalah antara lain :

a. Konsep logika fuzzy mudah untuk dipahami karena konsep matematis yang mendasari penalaran fuzzy sangat sederhana. 
b. Logika fuzzy sangat fleksibel.

c. Logika fuzzy memiliki toleransi terhadap data-data yang tidak tetap.

d. Logika Fuzzy mampu memodelkan fungsi-fungsi non linear yang sangat kompleks.

e. Logika fuzzy dapat mengaplikasikan pengalaman para pakar tanpa secara langsung melalui proses pelatihan.

f. Logika fuzzy didasarkan pada bahasa alami.

\subsection{Himpunan dan Variabel Fuzzy}

Himpunan fuzzy pada dasarnya memiliki 2 (dua) macam atribut yang akan dibahas dibawah ini antara lain :

a. Atribut Linguistik yaitu penamaan suatu grup yang mewakili suatu keadaan atau kondisi tertentu dengan menggunakan bahasa alami. Contoh : KECIL, SEDANG, BESAR.

b. Atribut Numeris yaitu suatu nilai (angka) yang menunjukkan ukuran dari suatu variabel. Contoh : 40, 25, 60 .

\subsection{Fungsi Keanggotaan}

Fungsi Keanggotaan adalah suatu kurva yang menunjukkan pemetaan titik-titik input data ke dalam nilai keanggotaannya (derajat keanggotaan) yang mempunyai interval nilai 0 dan 1 . Terdapat beberapa pendekatan fungsi yang dapat di gunakan untuk mendapatkan nilai keanggotaan.

\subsection{Information Retrieval}

\subsubsection{Definisi Information Retrieval ${ }^{1}$}

Menurut Salton (1989) : "Information Retrieval systems mengolah sejumlah file kumpulan record dan permintaan informasi terhadapnya (query), dan mengidentifikasi serta mengambil sejumlah record dari file-file tersebut untuk merespon query. Pengambilan sejumlah record tergantung pada kecocokan antara record dan query, yang diukur dengan membandingkan sejumlah attribut (term) pada record dan query".

Menurut Kowalski (1997) : "Information Retrieval System adalah sebuah sistem yang dapat melakukan penyimpanan, penerimaan, dan pemeliharaan informasi. Informasi dalam konteks ini dapat terdiri dari teks (termasuk numerik dan data tanggal), citra, audio, video, and obyek multimedia lainnya).”

Disadur dari Wikipedia : "Information Retrieval adalah ilmu pencarian informasi dalam kumpulan dokumen, pencarian dokumen-dokumen itu sendiri, pencarian metadata yang mendeskripsikan dokumen-dokumen, atau pencarian teks, audio, citra atau data dalam database, termasuk database relasional itu sendiri atau database jaringan hypertext seperti Internet atau World Wide Web."

\footnotetext{
${ }^{1}$ http://tangra.si.umich.edu/ radev/650/notes; Modul Kuliah SI-650 Information Retrieval; University of Michigan, 2003.
} 


\subsubsection{Model dan Arsitektur Information Retrieval ${ }^{2}$}

Secara sederhana model dari Information Retrieval dapat di gambarkan sebagai berikut :

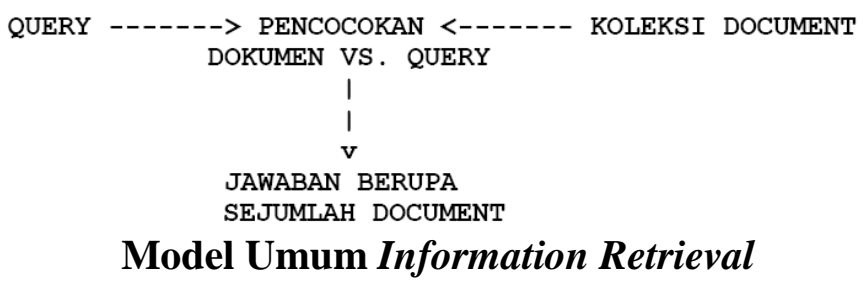

Sedangkan arsitektur dari Information Retrieval dapat di gambarkan sebagai berikut :

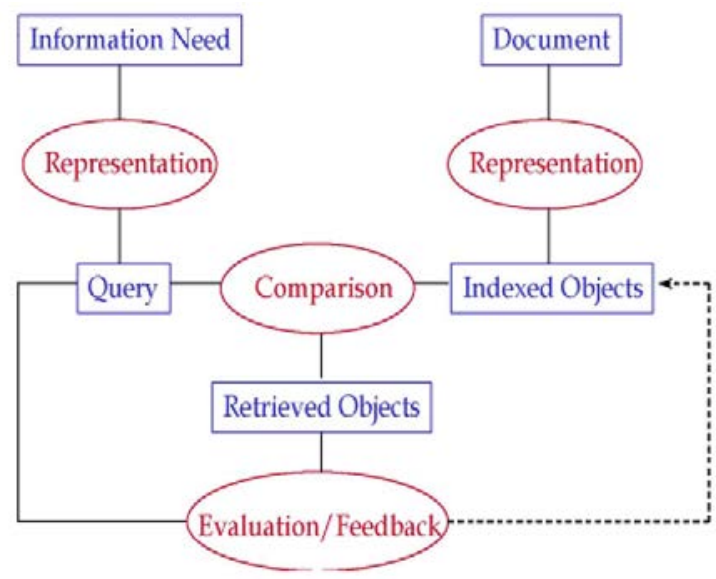

\section{Arsitektur Umum Information Retrieval}

Information Retrieval sendiri juga mempunyai beberapa model yang dapat dilihat dari tinjauan hasilnya yaitu :

a. Exact Match Retrieval

Query menspesifikasikan kriteria retrieval secara teliti. Setiap dokumen hanya disebut cocok atau gagal memenuhi query yang diberikan. Hasil retrieval adalah himpunan dari dokumen Biasanya tidak dalam urutan tertentu. Sering kali menggunakan reverse-chronological order $\rightarrow$ e.g., PubMed, karena yang terbaru akan lebih penting.

Contoh: Unranked Boolean retrieval model, termasuk Ranked Boolean retrieval model

b. Best Match Retrieval

Query mendeskripsikan kriteria retrieval untuk dokumen yang di harapkan. Setiap dokumen cocok dengan sebuah query pada tingkatan (degree) tertentu. Hasil selalu dalam daftar dokumen yang dilengkapi ranking, dimana "yang terbaik" diletakkan pada urutan pertama. Contoh: Vector Space Retrieval Model yang menggunakan term weights.

\footnotetext{
${ }^{2}$ James Thom ; Modul kuliah ISYS 1078/1079 Multimedia Information Retreival; IRmodelling.ppt (IR Modelling and Indexing)
} 


\section{Analisa dan Desain Sistem}

\subsection{Arsitektur Sistem}

Gambaran umum dari arsitektur sistem dapat di berikan dan di jelaskan pada gambar di bawah ini. Dalam arsitektur sistem terdapat 2 aktor yang terlibat dalam penggunaan sistem ini yaitu calon pembeli ponsel atau pengguna dan admin.

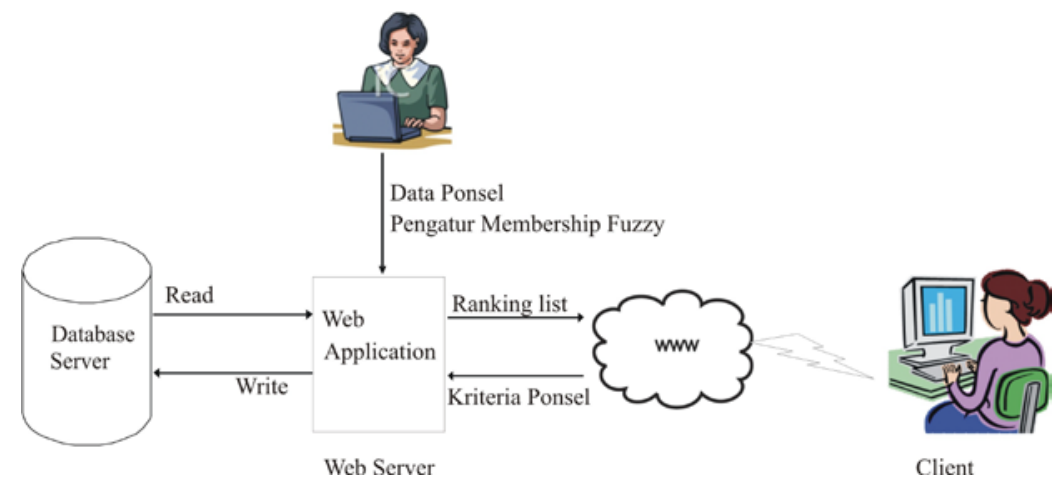

\subsection{Diagram Alir Data}

Agar sistem yang di buat terlihat lebih jelas, berikut di deskripsikan dengan Diagram Alir Data. Pada context model di bawah ini, digambarkan 2 entitas yaitu admin dan calon pembeli.

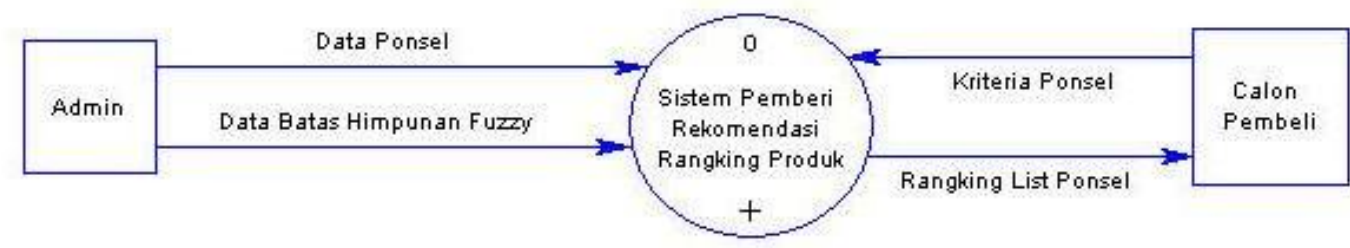

Context Model Sistem Pemberi Rekomendasi Rangking Produk

Dari sistem yang di buat, di harapkan bahwa sistem ini dapat memberikan kontribusi atau kemampuan berupa :

- Membantu calon pembeli ponsel dalam memberikan rekomendasi ponsel yang di inginkan sesuai dengan kriteria yang di-inputkan.

- Seluruh pengolahan data ponsel menggunakan logika Fuzzy yang di harapkan dapat memberi hasil yang optimal.

- Validitas batasan setiap kriteria pemilihan di ambil dari kuesioner yang telah di sebarkan kepada calon pembeli sehingga penentuan batasan-batasan tersebut menjadi sangat obyektif.

- Hasil atau keluaran yang di berikan kepada calon pembeli atas masukan kriteria ponsel berupa daftar peringkat produk (ranking list) ponsel, sehingga calon pembeli mendapatkan informasi yang akurat mana ponsel yang paling di rekomendasikan sesuai dengan kriteria-kriteria tersebut.

\section{Implementasi Sistem}

\subsection{Fitur dan Kemampuan Administrator}

Di dalam halaman ini terdapat beberapa fungsi yang bertugas mengendalikan dan mengontrol sistem di antaranya adalah kemampuan dalam menangani data ponsel yang meliputi menambah, merubah, menghapus data ponsel, menangani data gambar 
untuk ponsel, dan menangani batas-batas himpunan fuzzy. Secara Berikut penjelasan beberapa fitur admin yaitu :

1. Add Handphone $\rightarrow$ berfungsi untuk melakukan penambahan data ponsel.

2. Search Handphone $\rightarrow$ berfungsi untuk melakukan pencarian secara sederhana tentang data ponsel berdasarkan merk dan tipe ponsel.

3. Edit Handphone $\rightarrow$ berfungsi untuk melakukan perubahan data ponsel.

4. Upload Handphone Images $\rightarrow$ berfungsi untuk melakukan upload gambar ponsel yang selanjutnya akan di gunakan dalam proses entry data ponse,

5. Update Fuzzy Rule $\rightarrow$ berfungsi untuk melakukan proses perubahan nilai batas-batas himpunan fuzzy.

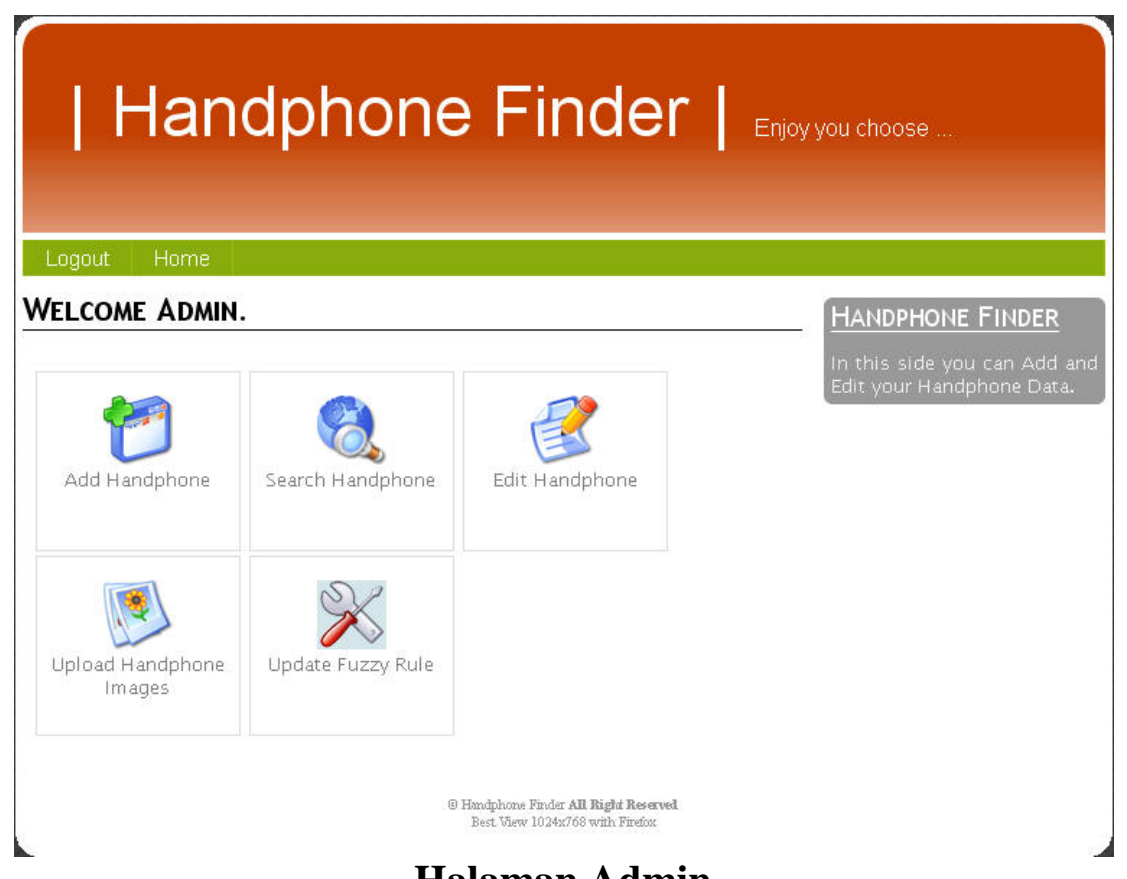

\section{Halaman Admin}

\subsection{Penanganan dan Pengelompokkan Data Ponsel}

Pada awal dari semua proses yang ada, pertama-tama admin akan meng-entry seluruh data ponsel berikut dengan gambar-gambar dari masing-masing ponsel. Data yang di-inputkan antaranya adalah :

Tabel Daftar Input Data Ponsel

\begin{tabular}{|l|l|}
\hline \multicolumn{1}{|c|}{ Nama Item } & \multicolumn{2}{|c|}{ Keterangan } \\
\hline Merk Ponsel & - \\
\hline Tipe Ponsel & - \\
\hline Dimensi Ponsel & $\begin{array}{l}\text { 1. Panjang, Tebal, } \\
\text { menggunakan satuan milimeter } \\
\text { (mm). }\end{array}$ \\
& 2. Berat, menggunakan satuan gram \\
\hline Ukuran Layar & Menggunakan satuan Pixel \\
\hline Internal Memori & $\begin{array}{l}\text { Menggunakan satuan Mega Bytes } \\
\text { (MB). }\end{array}$ \\
\hline Phone Book Memori & Menggunakan Satuan Buah \\
\hline
\end{tabular}


Tabel Daftar Input Data Ponsel

\begin{tabular}{|l|l|}
\hline \multicolumn{1}{|c|}{ Nama Item } & \multicolumn{1}{c|}{ Keterangan } \\
\hline Talk Time & Menggunakan Satuan Jam \\
\hline Stand By Time & Menggunakan Satuan Jam \\
\hline Panjang Karakter SMS & Menggunakan Satuan Karakter \\
\hline
\end{tabular}

Data-data yang di-entrykan tersebut di atas adalah data yang akan di gunakan sebagai kriteria dalam proses penghitungan nilai fuzzy. Selain itu masih terdapat datadata lain yang bersifat penunjang, yaitu data-data tentang fasilitas yang dimiliki oleh sebuah ponsel, yaitu :

1. Konektivitas (USB)

2. WAP

3. GPRS

4. Bluetooth

5. Infrared

6. 3G

7. Kamera

8. Games

9. MP3

10. Radio

11. Slot Memori Eksternal

12. Messaging (SMS, MMS, Email)

Kesemua data tersebut adalah data yang di golongkan input non Fuzzy, artinya masukan data tersebut tidak mempengaruhi kriteria dalam proses penghitungan nilai fuzzy, tetapi tetap masuk dalam kriteria tambahan dalam penyajian rekomendasi ponsel. Keseluruhan data yang di-entry, akan di kelompokkan berdasarkan merk ponsel dan tipe ponsel. Hal ini di lakukan untuk mempermudah proses pencarian mengingat banyaknya merk ponsel dalam database ini begitu pula dengan type setiap ponsel.

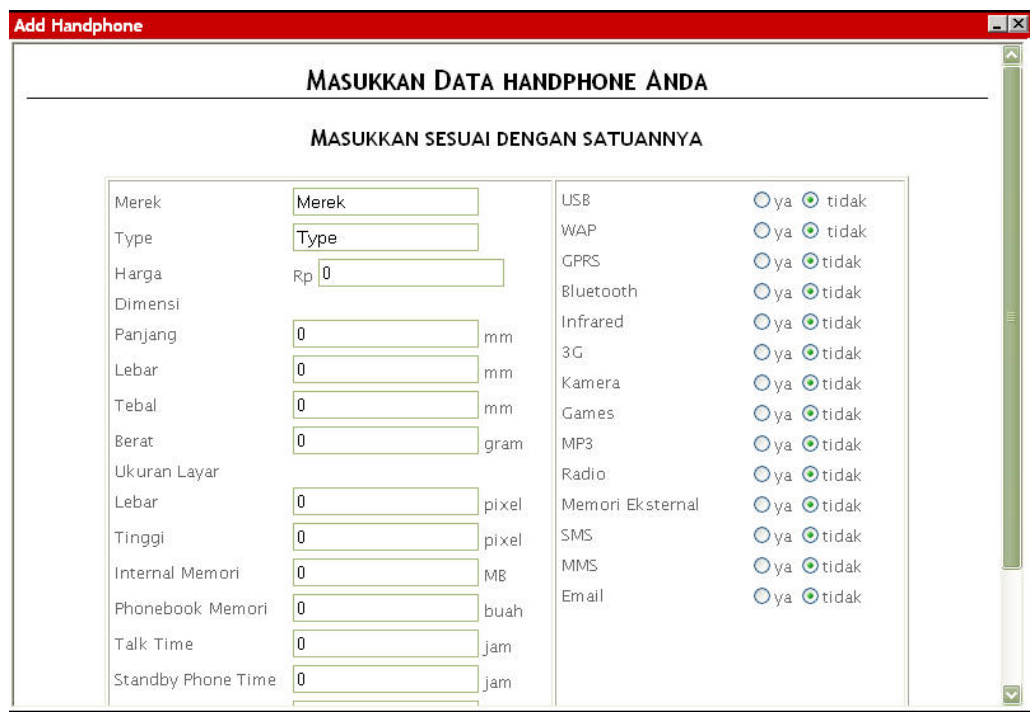

Halaman Entry Data Ponsel 


\section{3. $\quad$ Fitur dan Kemampuan Pengguna}

Di dalam halaman ini terdapat beberapa fungsi yang dapat di gunakan oleh pengguna di antaranya adalah melihat secara keseluruhan data ponsel yang ada, melakukan pencarian secara sederhana, melakukan pencarian tingkat lanjut. Berikut penjelasan beberapa fitur yang dimiliki pengguna yaitu :

1. Show All Handphone $\rightarrow$ berfungsi untuk menampilkan seluruh data ponsel yang terdapat dalam database. Fitur ini di gunakan apabila pengguna ingin melihat-lihat ponsel apa saja yang di miliki oleh sistem. Fitur ini juga dapat berfungsi sebagai katalog ponsel.

2. Advanced Search $\rightarrow$ Berfungsi untuk menampilkan data ponsel yang sesuai dengan kriteria pengguna. Di dalam halaman inilah pencarian berbasis fuzzy dilakukan.

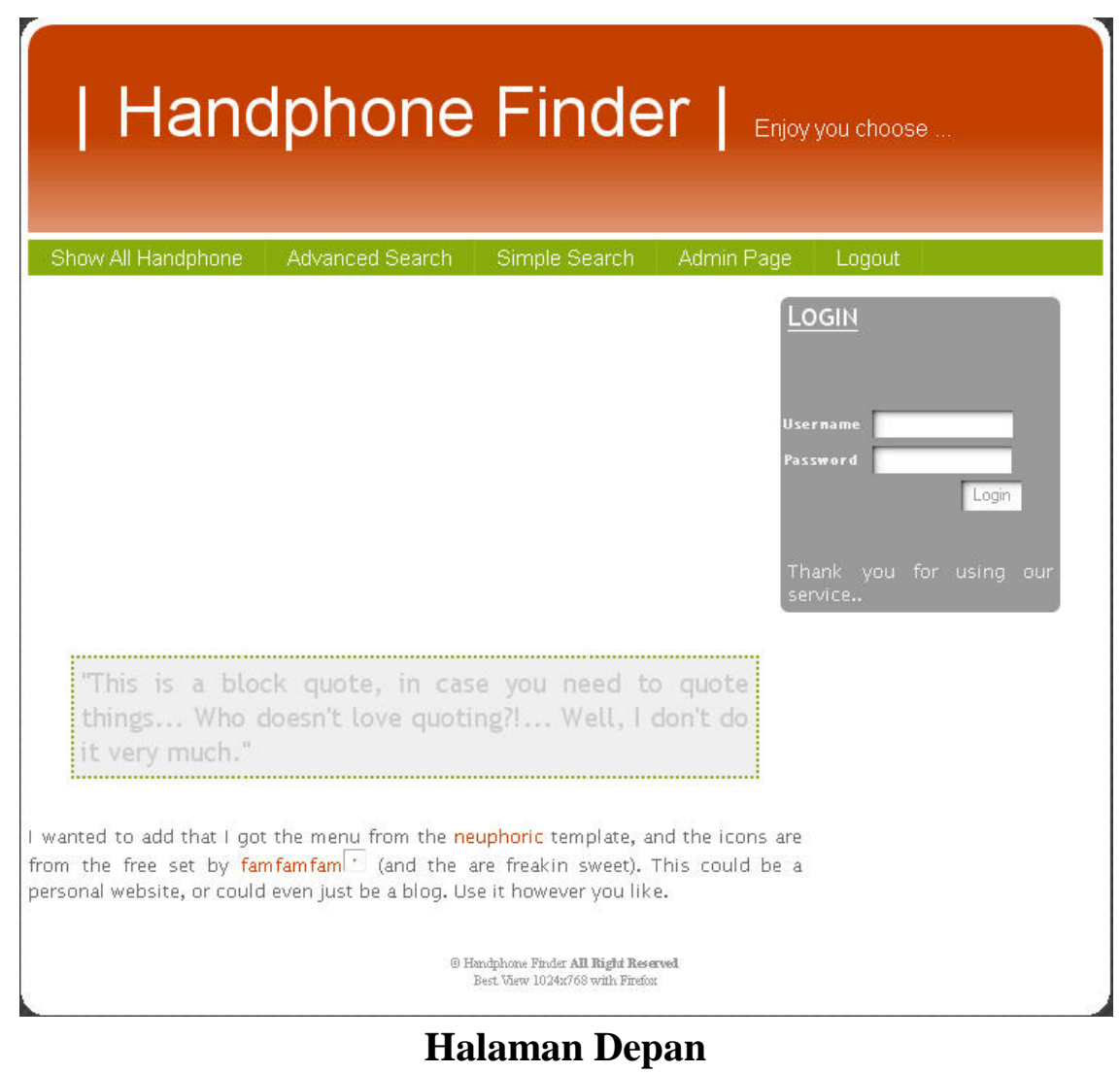

3. Simple Search $\rightarrow$ berfungsi untuk menampilkan data ponsel dengan proses pencarian sederhana. Proses pencarian ini sama dengan proses pencarian sederhana yang dipunyai oleh admin, hanya perbedaannya admin dapat melakukan perubahan dan penghapusan data, sedangkan pengguna hanya dapat melihat hasil pencarian tersebut. Hasil pencarian ini hanya berdasarkan dari merk ponsel dan tipe ponsel. 


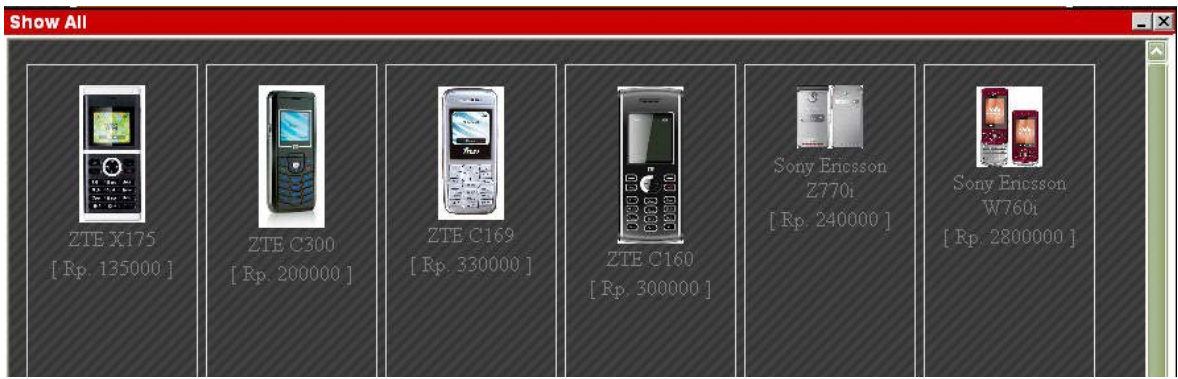

Menampilkan Seluruh Data Ponsel

\subsection{Pencarian Data Ponsel Berbasis Fuzzy}

Dalam menu selanjutnya yaitu Pencarian Berbasis Fuzzy, pengguna dapat melakukan proses pencarian berdasarkan kriteria yang dimiliki. Misalnya ingin mencari sebuah ponsel yang harganya "MURAH" dan beratnya "RINGAN". Selain itu dalam ponsel tersebut juga terdapat beberapa fasilitas yaitu : USB, WAP, GPRS, Bluetooth, 3G, Kamera, Games, MP3, Radio, Slot Memori Eksternal. Dari kriteria yang telah dimasukkan oleh pengguna tersebut, sistem akan memproses dan menampilkan seluruh data yang tersimpan dalam database.

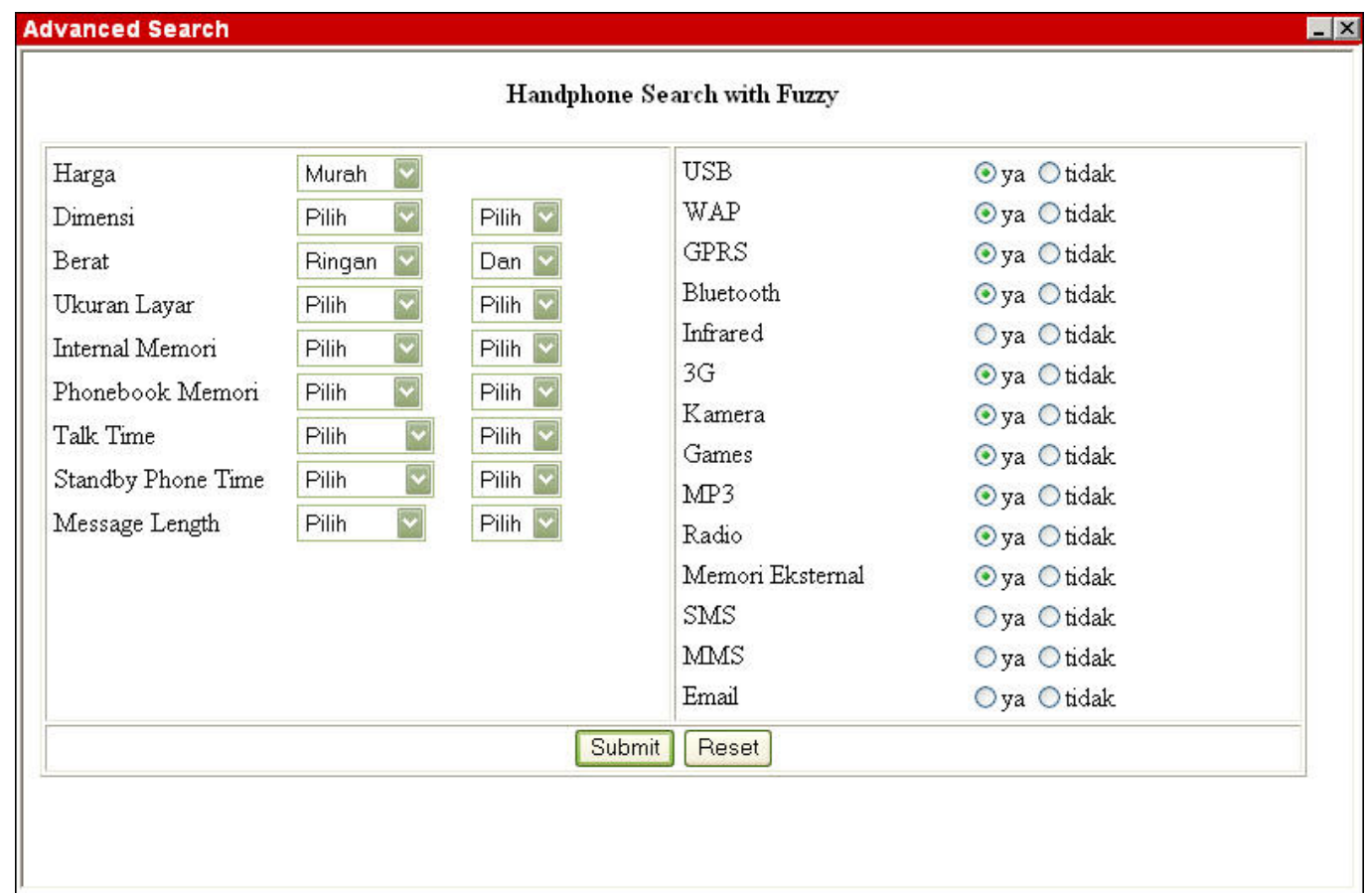

\section{Pencarian Data Ponsel Berbasis Fuzzy}

Setelah di lakukan proses pencarian tersebut, sistem akan menampilkan seluruh data ponsel yang sesuai dengan kriteria tersebut dalam bentuk peringkat. Mana ponsel yang paling di rekomendasikan sampai dengan ponsel yang punya nilai rekomendasi paling kecil. Di dalam penyajian data tersebut, juga di tampilkan hasil penghitungan nilai fuzzy sehingga menghasilkan nilai tersebut. Dalam proses pencarian ini, masukan pengguna dibagi menjadi dua bagian yaitu masukan yang mempunyai nilai fuzzy dan masukan yang tidak mempunyai nilai fuzzy. Seperti yang telah tertera pada gambar 4.7. dibagian sebelah kiri adalah masukan yang mempunyai nilai fuzzy sedangkan yang terletak di sisi sebelah kanan adalah masukan yang bernilai "Yes/NO” yang merupakan 
masukan non fuzzy. Masukan non fuzzy ini juga di kategorikan sebagai fasilitas dari ponsel tersebut. Proses yang di lakukan pertama kali adalah menghitung nilai derajat keanggotaan dari tiap kriteria input fuzzy yang selanjutnya akan di lakukan seleksi untuk mencari apakah fasilitas yang diminta oleh pengguna ada atau tidak dalam ponsel yang di rekomendasikan.

\begin{tabular}{|c|c|c|c|c|}
\hline \multicolumn{5}{|l|}{ Advanced Search } \\
\hline \multicolumn{5}{|l|}{$\leq<$ Back } \\
\hline $\begin{array}{l}\text { Rekomendasi } 1 \\
\text { LG KU250 } \\
\text { [Rp. 1000000] } \\
0.714286]\end{array}$ & $\begin{array}{l}\text { Rekomendasi } 2 \\
\text { Samsung Z170 } \\
\text { [Rp. 970000] } \\
\text { [Rekomendasi } \\
0.671429]\end{array}$ & $\begin{array}{c}\text { Rekomendasi } 3 \\
\text { Samsung L170 } \\
\text { [Rp. 1725000] } \\
\text { [Rekomendasi } \\
0.596154]\end{array}$ & $\begin{array}{c}\text { Rekomendasi } 4 \\
\text { LG KU380 } \\
\text { [Rp. 1260000] } \\
\text { [Rekomendasi } \\
0.58]\end{array}$ & $\begin{array}{l}\text { Rekomendasi } 5 \\
\text { Sony Ericsson } \\
\text { W600i } \\
\text { [Rp. 1700000] } \\
\text { [Rekomendasi } \\
0.54]\end{array}$ \\
\hline
\end{tabular}

\section{Hasil Pencarian Berbasis Fuzzy}

\section{Penutup}

\subsection{Kesimpulan}

- $\quad$ Setelah melalui tahap uji coba dengan menggunakan alat bantu aplikasi yang dibuat, aplikasi tersebut dapat memberikan rekomendasi sesuai dengan kriteria pengguna dimana masukan kriteria menggunakan bahasa sehari-hari dan dihitung dengan menggunakan logika fuzzy.

- Kuesioner yang disebarkan kepada responden cukup membantu dalam proses penentuan batas-batas himpunan fuzzy.

- Penggunaan representasi kurva segitiga lebih bermanfaat daripada kurva trapesium karena kurva segitiga dapat menghasilkan nilai rekomendasi lebih signifikan dibandingkan representasi kurva trapesium.

\subsection{Saran}

- Aplikasi ini dapat dikembangkan dengan mengacu pada perkembangan teknologi ponsel yang ada, misalnya fitur wi-fi, atau fitur-fitur yang lainnya.

\section{Daftar Pustaka}

D. Cox, Earl. 1995. Fuzzy Logic for Business and Industry. New York : Charles River Media, Inc.

Kusumadewi, Sri. 2004. Aplikasi Logika Fuzzy untuk Pendukung Keputusan. Yogyakarta : Graha Ilmu.

Setiawan, Kuswara. 2001. Paradigma Sistem Cerdas. Surabaya

http://tangra.si.umich.edu/ radev/650/notes; Modul Kuliah SI-650 Information

Retrieval; University of Michigan, 2003.

http://www.wikipedia.com 